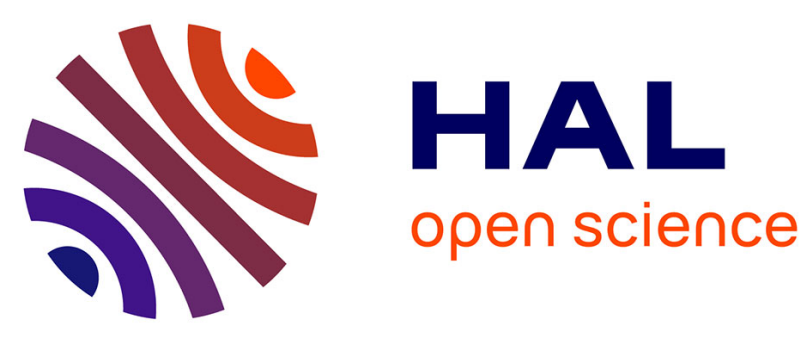

\title{
Hematopoietic cell transplant nurse coordinators' perceptions of related donor care: a European survey from the EBMT Nurses Group
}

Alice Poloméni, C. Bompoint, M. Labopin, M. Badoglio, G. Battipaglia, C. Eeltink, S. J Liptrott, A. Babik, J. E Murray, J. Stringer

\section{To cite this version:}

Alice Poloméni, C. Bompoint, M. Labopin, M. Badoglio, G. Battipaglia, et al.. Hematopoietic cell transplant nurse coordinators' perceptions of related donor care: a European survey from the EBMT Nurses Group. Bone Marrow Transplantation, 2020, 55 (3), pp.623-632. 10.1038/s41409-019-0686-y . hal-03094365

\section{HAL Id: hal-03094365 \\ https://hal.sorbonne-universite.fr/hal-03094365}

Submitted on 4 Jan 2021

HAL is a multi-disciplinary open access archive for the deposit and dissemination of scientific research documents, whether they are published or not. The documents may come from teaching and research institutions in France or abroad, or from public or private research centers.
L'archive ouverte pluridisciplinaire HAL, est destinée au dépôt et à la diffusion de documents scientifiques de niveau recherche, publiés ou non, émanant des établissements d'enseignement et de recherche français ou étrangers, des laboratoires publics ou privés. 


\section{Title Page}

Title of the paper :

Hematopoietic cell transplant nurse coordinators' perceptions of related donor care: a European survey

Running title : Related-donor care: a European survey

\section{Authors :}

A. Polomeni ${ }^{1 *}$, C. Bompoint ${ }^{2}$, M. Labopin ${ }^{3 *}$, M. Badoglio ${ }^{3 *}$, G. Battipaglia ${ }^{1}$, C. Eeltink ${ }^{4}$, SJ Liptrott $^{5}$, A. Babik 6 , J. Murray7 ${ }^{7}$ J Stringer ${ }^{8}$

1. Department of Hematology and Cell Therapy, Saint-Antoine Hospital, Paris, France.

2. Department of Hematology and Cell therapy, Saint Eloi Hospital, Montpellier, France ;

French EBMT Nurse Group, EBMT Nurses Group

3. EBMT Paris Study Office / CEREST-TC, Department of Hematology and Cell Therapy, Saint-Antoine Hospital, INSERM UMR 938, Université Pierre et Marie Curie, Paris, France 4. Amsterdam UMC, VU University Medical Center Department of Hematology

The Netherlands, EBMT Nurses Group

5. IEO, European Institute of Oncology IRCCS, Milan, Italy, EBMT Nurses Group

6. IOSI-Istituto Oncologico della Svizzera Italiana, Switzerland, JACIE QM Inspector, EBMT Nurses Group

7. Haematology and Transplant Unit, Christie Hospital NHS Foundation Trust

Manchester, EBMT UK Nurses and Allied Professionals Group, EBMT Nurses Group

8. The Christie NHS Tust, Manchester, The University of Manchester, UK, EBMT Nurses Group.

* These authors contributed equally to this work.

\section{Corresponding author :}

\section{Alice POLOMENI}

Service d'Hématologie clinique et thérapie cellulaire

\section{Hôpital Saint Antoine}

184 rue du Fbg St Antoine

75012 Paris- France

Phone number : + 33149283438

Fax number : + 33149283200

alice.polomeni@aphp.fr 
1 Hematopoietic cell transplant nurse coordinators' perceptions of related donor 2 care: a European survey

3

4 Abstract

5

6

7 through a prospective study.

\section{Abstract}

Allogeneic 3 related-donation.

patients with haematological malignancies and immune deficiencies.

8 A human leukocyte antigen identical sibling is only available for $25-35 \%$ of patients in 9 need. The improvement in haplo-identical transplantation has led to a marked increase in cell donation from relatives. Despite international recommendations, discrepancies in related-donors care exist between centres, particularly regarding medical suitability criteria, consenting procedures and donor follow-up. This European survey aimed to explore Hematopoietic Cell Transplantation Coordinators Nurses' (HCT-CNs) perceptions of related-donor (RD) care, in particular the association with the presence or not of an independent unit (IU). Ninety-three HCT-CNs from 76 EBMT centres responded, representing 19 countries (response rate: $27 \%$ ).

1 Our results did not show a significant association between IU and HCT-CNs perceptions 8 of related-donors care. We noted heterogeneity between the European HCT teams' practices regarding RD care. Qualitative data highlights related-donation ethical issues and the need for improvement in RD care. HCT-CNs' main concerns were: the necessary 21 confidentiality to insure the voluntary status of $\mathrm{RD}$, the perceived conflict of interest felt 2 by professionals when managing both patients and $\mathrm{RD}$, plus the psychosocial aspects of 
Allogeneic Haematopoietic Cell Transplantation (HCT) is a curative procedure for patients with haematological malignancies and immune deficiencies. A human leukocyte antigen (HLA)-identical sibling is available for only $25-35 \%$ of patients in need ${ }^{1}$. For patients lacking a fully matched sibling donor, other cell sources are available such as unrelated donors (UD), umbilical cord blood units or an HLAmismatched family donor (HAPLO) ${ }^{2}$. The recent use of non T-cell depleted haploidentical HCT with new strategies to modulate donor T-cell alloreactivity has resulted in significant improvement of results. 3, 4, 5, 6 These techniques have contributed to an increased number of HAPLOs in recent years ${ }^{7,8}$. Cell donation from relatives presents lower financial costs and a faster availability but raises specific clinical and ethical issues ${ }^{1}$.

The World Marrow Donor Association recommends that related donors (RD) be assessed by a physician from an Independent Unit (IU) and not involved with the recipient's treatment ${ }^{9}$. This independent evaluation is also required by the Joint Accreditation Committee Standards (JACIE). ${ }^{10}$. However, to date practices regarding RD

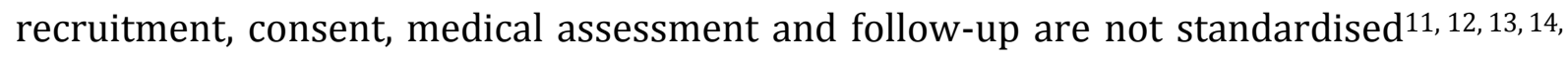
15.

In the United States, despites significant improvements in patterns of practice, HCT teams (HCT-Coordinators Nurses and HCT-physicians) remain involved in RD care in $38 \%$ of the participant centres, with these centres performing $79 \%$ of the American transplants ${ }^{11,12}$.

A European survey performed in 2005 identified that RDs were informed about harvesting procedures and donation processes by the recipient's transplant team in $57 \%$ of HCT units ${ }^{15}$. However, this survey is over a decade old, has several limitations (population selection, low participation rates, regional bias) and therefore cannot be taken as representative of current European practice.

The current practice of caring for both RD and recipient may affect ethical, psychosocial and medical aspects of RD care. Significant differences have been reported in the medical management of UD and RD regarding eligibility criteria (age limit, accepted comorbidities) and donation parameters (GSF-doses, number of collections and collected volume ${ }^{16}$. 
The quality of information delivered, the adequacy of donor preparation and the emotional support provided by HCT teams have an impact on RD experience 17, 18,19, 20 . These essential tasks (e.g. provision of information, organization of donation process and emotional support) are primarily carried out by HCT-coordinators Nurses (HCTCNs). A French survey highlighted the perceived conflict of interest felt by HCT-CNs when managing both the patient and RD impacting negatively on RD's information, consent and care. HCT-CNs suggestions to improve RD care were focused on ethical and psychosocial issues, from information provided prior to HLA typing to post-donation follow-up procedures ${ }^{21}$.

The negative effects of cell donation such as pain, fatigue, psychological morbidity and the risks of severe adverse events, have all been well described. ${ }^{22,23}$ However, the quality of the care offered to RD has not been investigated.

The Research Committee of the EBMT Nurses Group have supported this European survey with the aim of exploring HCT-CNs perceptions of RD care, focusing on the comparison between HCT-CNs working in an IU with those from a Non-Independent Unit (NIU).

\section{Methods}

Ethical approval was not required for this survey.

The primary objective was to study the associations between unit type (IU or NIU), reported RD care organization and difficulties met by HCT-CNs. The secondary objective was to search for potential factors associated with donor difficulties (practical, financial, relational and psychological).

An electronic survey was designed, accessible to all HCT-CNs registered in EBMT adult centres performing HCT. The survey was released in April 2016. HCT-CNs were contacted via an email, which included a direct web-link to the survey and invited to participate. The request was repeated several times until the end of September 2016.

The survey consisted of 47 questions divided in three topics: A) HCT-CNs characteristics (age, professional experience); B) units' donation procedures (information provision for potential donors, HLA test procedures, consent process, availability of financial support and donor follow-up) and C) HCT-CNs' perceptions of the RD care.

The survey included single and multiple choices questions. Open-ended questions were also asked in order to gain HCT-CNs' opinion about processes relating to RD care, RD 
93 concerns and suggestions on possible ways to improve the organization of related

94 donation (See Appendix 1).

Statistical methods

97 All categorical data were presented using frequency counts and percentages.

98 The two groups of responders (those working in IU versus NIU) were compared by 99 using $\chi^{2}$ statistics. Factors associated with IU or NIU with a p value less than 0.10 in 100 univariate analysis were included in a multivariate logistic regression model for binary 101 variables. Results were presented as odd ratios (OR) and 95\% confidence intervals (CI). 102 Statistical analyses were performed with SPSS 24.0 (SPSS Inc, Chicago, IL, USA).

Thematic analysis

105 The answers to open-ended questions were subject to thematic analysis using the 106 Framework approach: researchers identify a priori themes from existing knowledge of 107 the topic and used these to guide and structure the analysis. The Framework approach 108 allows for a combination of theme-based and case-based analyses, which was 109 appropriate in this study. This method, with clear steps to follow, is recognized as 110 rigorous and systematic in qualitative analysis $24,25$.

111 We used NVIVO software to manage qualitative data ${ }^{26}$. Two investigators independently 112 coded the answers, and a third investigator reviewed this coding and participated in the 113 thematic analysis. The interpretations given by the three investigators were then 114 validated by other co-authors (consensual validity). An example of the analysis 115 procedure using the framework method can be seen in Appendix 2.

\section{Results}

118 HCT-CNs characteristics

119 An overall response rate of $27 \%$ was achieved with 93 HCT-CNs from 76 EBMT centres, 120 representing 19 countries replying. France, United Kingdom, The Netherlands and Italy 121 accounted for $65 \%$ of all responders.

122 Table 1: shows socio-demographic characteristics, academic qualifications and 123 professional experience of the HCT-CNs. Seventy-six percent of responders had worked 124 in haematology units for over 10 years and 69\% possessed more than 6 years' 125 experience as an HCT-CN. 
127 Organisation of RD care

128 Table 2a: summarizes responses relating to organization of RD care. Forty-eight percent

129 of respondents worked in an IU.

130 HCT-CNs' perceptions of RD care

131 Table 2b: summarizes replies pertaining to difficulties experienced by HCT-CNs when

132 undertaking RD care. HCT-CNs reported that their role in RD care was mainly related to 133 information provision (80\%), psychosocial support (70\%) and follow-up (54\%). 134 Twenty-nine percent of HCT-CNs reported conflict of interest when caring for both RD 135 and recipients, 81\% responded that they had experienced demanding situations and 136 61\% perceived that related-donation had been difficult for the RD and/or the recipient.

138 Comparison of RDs care organization according to IU

139 Table 3: summarizes the results of the comparison between IU and NIU with regard to 140 care of RD, the existence of different pathways for recipients and RD.

142 The HCT team were the first to address the issue of stem cells donation with the patient 143 [44\% IU vs. 31\% NIU, p=NS] and with the potential RD [66\% IU vs. 62\% NIU, p=NS]. 144 Patients were requested to contact potential RD in $27 \%$ of IU and in $13 \%$ of NIU [p=NS].

145 There was no difference between IU and NIU regarding the information provided to the 146 RD in relation to donation / transplant before HLA typing and materials such as booklets 147 were frequently available [62\% IU vs. 73\% NIU, p=NS]. A specific interview to provide 148 information to a compatible RD was organized at the time of the pre-donation work-up 149 in $91 \%$ of IU and $92 \%$ of NIU [p=NS].

150 The organization of RD follow-up was no different between IU and NIU. Most of the 151 units (78\%) did organize a RD follow-up: a single evaluation during the first year post152 donation [76\% IU vs. 81\% NIU, p=NS].

153 By multivariate analysis (Table 4), IU were associated with a higher number of donors 154 (>=20 per year) (OR: 1.63; 95\% CI: 1.14-2.32; p=0.007) and less frequent 155 communication of results of HLA typing to the patients (OR: 0.33; 95\% CI: 0.12-0.89; $156 \mathrm{p}=0.03)$. No other significant differences were found between IU and NIU. 
158 Comparison of HCT-CNs' perceptions of RD and difficulties in RD care according to the

159 type of unit

160 For 73\% IU vs. 71\% NIU of HCT-CNs, RD needs are addressed in their unit, p=NS. HCT-

161 CNs experienced difficulties in RD care in both IU and NIU (80\% vs. 82\%, respectively, $162 \mathrm{p}=\mathrm{NS})$. Forty-five per cent of the HCT-CNs agreed with the following statement: « The 163 only way to protect RDs' free choice to give or not, is to organize RDs' care within a fully 164 independent unit ». In NIU, there was a trend towards agreement with this statement in 165 respondents who perceived conflicts of interest (40\%) vs those who did not (17\%) $166(\mathrm{p}=0.086)$. See Table 3.

\section{Qualitative data}

169 Themes identified from analysing HCT-CNs comments were related to ethical and 170 psychological matters associated with RD care. Ethical issues were mainly linked to 171 doubts about assuring freedom of choice to RD. HCT-CNs experienced helplessness 172 when facing RD ambivalence or even withdrawal of donation. They considered RD care 173 "very medically driven" and stressed the need of psychological support.

174 Some HCT-CNs believe that a completely IU is required to offer a RD the necessary 175 conditions for free choice and quoted examples of conflict of interest. Respondents who 176 disagreed with this proposition considered that having separate care pathways for RD 177 and recipients, in the same HCT-Unit could be the answer to the ethical concerns 178 associated with RD care.

179 These differing opinions reflect HCT-CNs' own perspective on related-donation and their 180 role in RD care. Related-donation is perceived as being driven by family's history and 181 emotional links, so that different kinds of care organization couldn't influence RD 182 dilemma. Conversely, HCT-CNs see their professional skills as the answer to demanding 183 situations, which could raise conflict of interest between RD difficulties and recipients' 184 needs. Illustrative quotations of qualitative data are shown in Table 5.

\section{Discussion}

187 The expertise and professional experience of responders to our survey provide a valid 188 basis for discussing the different ways to improve RD care.

189 We aimed to explore HCT-CNs' point of view about RD care organization and 190 independent unit relevance. Our hypothesis was that a specific Unit for donor care 28,29 
191 would ensure RD safety, anonymity and confidentiality. This is a crucial issue in RD care 192 and its' feasibility has been discussed by different authors $9,27,30,36$. In our study, we did 193 not find any association between IU, RD care organisation and difficulties in RD care. 194 The only factor associated with the presence of an IU was a greater number of RD seen 195 per year. This may indicate that for HCT units caring for a smaller number of RD, it may 196 be difficult to organise an independent unit.

197 Our results show that current RD care organization does not always prevent ethical issues and may generate conflict of interest for HCT teams. Previous studies have shown 199 that ethical issues, namely the lack of anonymity and confidentiality, are related to 200 practical aspects of RD care: contact with potential donors, information before HLA 201 typing and HLA results' disclosure $11,12,14,15$.

202 The first contact is a relevant issue for a potential RD who, asked to donate by the recipient or by another close relative, may feel that they have no real volunteer status 21,31. In our survey, initial contact was made by HCT teams in the majority of centres.

205 Providing exhaustive information before HLA typing is one way to avoid related 206 donation to become a «mandatory act »9. Additionally, RD understanding of the HCT 207 process may temper " unrealistic expectations» and decrease their emotional distress 208 when recipient's outcome is not favorable ${ }^{32}$. In our study, most of the respondents 209 declare that a potential RD was informed about donation and transplant before HLA 210 typing with a written information (booklet), whereas in Clare et al. ${ }^{15}$ survey, a quarter of 211 respondents used only verbal methods to inform a RD.

212 As previously noted in American centres ${ }^{12}$, HLA typing results may be disclosed to the 213 patients. Such a disclosure is clearly a breach of confidentiality since the results are the 214 'property' of the potential RD. In our study, HLA typing results were first communicated 215 to the patient in more than half of the cases.

216 This point illustrates that current practices could be improved. Patterns of recruitment, 217 assessment and care of the RD still lead HCT teams to be in conflict of interest. Quoting 218 El-Ghariani and Dalle 36 , "a major dilemma in donor ethics is the fact that assessing harm 219 and inconvenience to one person (the donor) in relation to expected benefits to 220 another". In our survey, 81\% of HCT-CNs reported difficulties in RD care and 29\% have 221 been torn between the recipients' and the donors' needs.

222 This issue had not been raised by Clare et al. ${ }^{15}$ or by any other authors before the 223 publication of the French survey ${ }^{21}$ in 2016 . This last study indicated that even with a 
224 specific care pathway for RDs, HCT-P and/or HCT-CN could be involved in discussion 225 regarding the recipients. Having information about recipients' diagnosis and personal 226 circumstances may influence the HCT team's capacity to cope with reticence to donate. 227 For O'Donnel et al. ${ }^{11}$, the conflict of interest experienced by HCT teams could explain the 228 differences observed between RD and UD management (medical criteria for recruitment 229 and treatment). Anthias et $\mathrm{al}^{27}$ discuss pros and cons of the UD Registry's involvement in 230 RDs management, as a way to reduce organisational discrepancies between UD and RD 231 care, to homogenize donors' suitability criteria and to avoid potential conflicts of 232 interest.

233 In our study, although one-third of HCT-CNs reported conflict of interest when caring for 234 both RD and recipient, 55\% of them considered that different pathways within the same 235 HCT unit would be a suitable answer to ethical issues in RD care. According to our 236 qualitative data, this opinion is linked to HCT-CNs' representations of related-donation 237 inherent dilemmas, but could also be partly related to HCT-CNs' concerns about losing 238 their current pivotal role in RD care.

239 HCT-CNs asked for more manpower and for the standardization of RD care. They 240 emphasized that psychosocial needs of the RD are not met by the current organization of 241 care. HCT-CNs referred to RD feelings of "being neglected", worrying about HCT failure 242 and longing to be reassured by medical teams ${ }^{32}$. In light of the HCT-CNs comments, 243 follow-up should consider the psychological condition of a RD, especially in cases of 244 severe complications such as GvHD, relapse or death of the recipient. Studies comparing 245 bereaved and not-bereaved RD reveal contradictory results regarding psychological 246 condition ${ }^{33,34}$, but qualitative studies have shown that despite their intellectual 247 understanding of HCT process, a RD may feel guilty in cases where the recipients have 248 experienced adverse outcomes ${ }^{32}$.

249 Van Walraven et al. ${ }^{35}$ have drawn attention to the experience of parents requested to 250 become donors in haplo-identical HCT. The authors stress the difficulty of managing the 251 dual role of donor and caregiver for their ill child. We could also hypothesize that the 252 inversion of roles may be challenging for both donors and recipients when children are 253 asked to give HSC to their parents. Although the psychosocial impact of related-donation 254 has been demonstrated, these issues of haplo-identical transplantation should be further 255 explored. 
256 Our survey has raised significant questions, but it has several limitations. The 257 participation reached $27 \%$ of the EBMT centres. Although 19 countries participated in

258 the survey, we cannot ascertain its representativeness among all EBMT centres.

259 We decided to exclude pediatric HCT units, because care of children raises specific 260 issues, notably the parents' participation during the all procedure.

261 In depth interviews could be of interest to complete our qualitative data, and enhance 262 understanding of HCT-CNs work conditions and ethical dilemma.

263

\section{Conclusion}

265 Our survey showed the heterogeneity of practice within European HCT teams relating 266 to the care of the RD. Qualitative data highlights related-donation ethical issues and the 267 need for improvement in RD care. The necessary confidentiality to insure the voluntary 268 status of a RD and the psychosocial aspects of related-donation are HCT-CNs' main 269 concerns. Despite the perceived conflict of interest felt by professionals when managing 270 both recipients and RD, a completely IU is not recognized by all HCT-CNs as being the 271 solution to RDs care ethical issues. A full understanding of RD care issues requires an 272 exploration of RD experiences through a prospective study.

273

\section{Conflict of interest}

275 The authors declare no conflict of interest

277 Supplementary information is available at Bone Marrow Transplantation's 278 website:

279 Appendix 1 - The questionnaire

280 Appendix 2 - Example of Framework analysis' process 
1. Boo M, van Walraven SM, Chapman, J, Lindberg B, Schmidt AH, Shaw BE. on behalf of the World Marrow Donor Association. Remuneration of hematopoietic stem cell donors: Principles and perspective of the World Marrow Donors Association. Blood, 2011; 117 : 21-25.

2. Kekre N, Antin JH. Hematopoietic stem cell transplantation donor sources in the 21st century: choosing the ideal donor when a perfect match does not exist. Blood 2014; 124(3):334-343.

3. Bashey A., Zhang X, Sizemore CA. Manion K, Brown S, Holland HK et al. T-Cell-Replete HLA-Haploidentical Hematopoietic Transplantation for Hematologic Malignancies Using Post-Transplantation Cyclophosphamide Results in Outcomes Equivalent to Those of Contemporaneous HLA-Matched Related and Unrelated Donor Transplantation. J Clin Oncol $2013 ; 31: 1310-1316$. Transplantation Cyclophosphamide Based Haploidentical Transplantation as Alternative to Matched Sibling or Unrelated Donor Transplantation for Hodgkin Lymphoma: A Registry Study of the Lymphoma Working Party of the European Society for Blood and Marrow Transplantation. J Clin Oncol. 2017 ; 35(30):3425-3432.

5.Raiola AM, Dominieto A, di Grazia C. Lamparelli T, Gualandi F, Ibatici A, et al Unmanipulated Haploidentical Transplants Compared with Other Alternative Donors and Matched Sibling Grafts Biol Blood Marrow Transplantation; 2014; 20 :1573-1579.

6. Kanate AS, Mussetti A., Kharfan-Dabaja MA. Reduced-intensity transplantation for lymphomas using haploidentical related donors vs HLA-matched unrelated donors. Blood 2016;127(7):938-947.

7. Passweg JR, Baldomero H, Bader P, Bonini C, Cesaro S, Dreger P, Mohty M. Hematopoietic SCT in Europe 2013: Recent trends in the use of alternative donors showing more haploidentical donors but fewer cord blood transplants. Bone Marrow Transplantation $2015 ; 50: 476-482$.

8. Passweg JR, Baldomero H, Badera P, Bonini C, Duarte RF, Dufour C et al. for the European Society for Blood and Marrow Transplantation (EBMT). Use of haploidentical stem cell transplantation continues to increase: the 2015 European Society for Blood and Marrow Transplant activity survey report. Bone Marrow Transplantation 2017; 52(6):811-817. 
9. Van Walraven SM, Nicolo-de-Faveri G, Axdorph-Nygell UA, Douglas KW, Jones DA, Lee SJ, on behalf of the World Marrow Donors Association Ethics and Clinical working groups. Family donor care management: Principles and recommendations. Bone Marrow Transplantation $2010 ; 45: 1269-1273$.

10. JACIE. International standards for hematopoietic cellular therapy product collection, processing and administration. [http://www.jacie.org].

11. O’Donnel PV, Petersen TL, Confer DL, Rizzo JD, Pulsipher MA, Stroncek D, Anderlini P. Practice patterns for evaluation, consent and care of related donors and recipients at hematopoietic cell transplantation centers in the USA. Blood $2010 ; 115,5097-5101$.

12. Anthias C, Shaw BE, Kiefer DM, Liesveld JL, Yared J, Kambl RT et al. Significant Improvements in the Practice Patterns of Adult Related Donor Care in US Transplantation Centers. Biol Blood Marrow Transplant 2017; 22: 520-527.

13. Coluccia P, Crovetti G, Del Fante C, Dallavalle FM, Laszlò D, Ferremi P et al. Screening of related donors and peripheral blood stem cell collection practices at different Italian apheresis centres. Blood Transfus 2012; 10: 440-447.

14. Anthias C, Peniket A, Kirkland K, Madrigal JA, Shaw BE. Variations in practice in UK transplant centers: results of a related donor care survey Bone Marrow Transplantation $2016 ; 51: 1612-1614$.

15. Clare S, Mank A, Stone R, Davies M, Potting C, Apperley JF, on behalf of the Research Sub-committee of the European Group for Blood and Marrow Transplantation Nurses Group. Management of related donor care: A European survey. Bone Marrow Transplantation $2010 ; 45: 97-101$ G, Confer D. Allogeneic hematopoietic stem cell donation - standardized assessment of donor outcome data: A consensus statement from the Worldwide Network for Blood and Marrow Transplantation (WBMT). Bone Marrow Transplantation 2013 ; 48 : 220-225.

17. Muzenberger N, Fortanier C, Macquart-Moulin G, Faucher C, Novakovitch G, 360 Maraninchi D, Blaise D. Psychosocial aspects of hematopoietic stem cell donation for 361 allogeneic transplantation: How family donors cope with this experience. Psychooncology 1999 ; 8 : 55-63. 
19. Williams S, Green R, Morrison A, Watson D, Buchanan S. The psychosocial aspects of donating blood stem cells: The sibling donor perspective. Journal of Clinical Apheresis $2003 ; 18: 1-9$.

20. Pillay B, Lee SJ, Katona L, De Bono S, Warren N, Fletcher J, Burney S. The psychosocial impact of hematopoietic SCT on sibling donors. Bone Marrow Transplantation $2012 ; 47: 1361-1365$.

21. Polomeni A, Bompoint C, Gomez A, Brissot E, Ruggeri A, Belhocine R, Mohty M. Current practices for screening, consent and care of related donors in France: haematopoietic stem cell transplantation coordinator nurses' perceptions. European Journal of Cancer Care 2016 ; 00:1-15. doi: 10.1111/ecc.12612

22. Halter J, Kodera Y, Ispizua AU, Greinix HT, Schmitz N, Favre G, Gratwohl A. Severe events in donors after allogeneic hematopoietic stem cell donation. Haematologica $2009 ; 94$ : 94-101.

23. Siddiq S, Phamphilon D, Brunskill S, Doree C, Hyde C, Stanworth S. Bone marrow harvest versus peripheral stem cell collection for haemotopoietic stem cell donation in healthy donors. Cochrane Database Systematic Review 2009; 21(1): CD006406. doi:10.1002/14651858.CD006406

24. Ward DJ, Furber C, Tierney S, Swallow V. Using FrameworkAnalysis in nursing research: a worked example. Journal of Advanced Nursing 2013 ; 69(11), 2423 :2431.

25. Smith J., Firth J. Qualitative data analysis: the framework approach. Nurse Researcher $2011 ; 18(2), 52-62$.

26. NVivo Qualitative Data Analysis Software Version 8. QSR International Pty Ltd, 2008.

27. Anthias C, vanWalraven SM, Sorensens, de Faveri GN, Fechter M, Cornish J et al. Related hematopoietic cell donor care: is there a role for unrelated donor registries ? Bone Marrow Transplantation 2015; 50 :637-641.

28. Muramatsu H, Kimura S, Ichinohe T, Ashihara E, Ishikawa T, Maekawa T, Uchiyama T. Consulting clinic for related family donors in hematopoietic stem cell transplantation. Bone Marrow Transplantation 2008 ; 41 : 1073-1075.

29. Kisch A, Dykes J, Lindmark A, Lenhoff S. A proposed plan for the management of adult sibling donors. Bone Marrow Transplantation 2008; 42: 357-358; 
30. Billen A, Madrigal JA, Shaw BR. A review of hematopoietic stem cell donation experience: is there room for improvement? Bonne Marrow Transplantation 2014; $410 \quad 49: 729-736$.

31. Kisch A, Lenhoff S, Bengtsson M, \& Bolmsjö I. Potential adult sibling stem cell donors' perceptions and opinions regarding an information and care model. Bone Marrow Transplantation $2013 ; 48,1133-1137$.

32. Garcia MC, Chapman JR, Shaw JP, Gottlieb DJ, Ralph A, Craig JC, Tong A. Motivations, 417 Experiences, and Perspectives of Bone Marrow and Peripheral Blood Stem Cell Donors: 418 Thematic Synthesis of Qualitative Studies. Biol Blood Marrow Transplant 2013; $419 \quad 19: 1046-1058$.

33. Switzer GE, Dew MA, Magistro CA, Goycoolea JM, Twillman RK, Alter C, Simmons RG.

422 The effects of bereavement on adult sibling bone marrow donors' psychological wellbeing and reactions to donation. Bone Marrow Transplantation 1998; 21 :181-188.

34. Chang G, McGarigle C, Koby D, Antin JH. Symptoms of pain and depression in related marrow donors: Changes after transplant. Psychosomatics 2003;44:59-64.

35. Van Walraven SM, Ball LM, Koopman HM, Switzer GE, Ropes-de Jong CM, de Jong A, et al. Managing a dual role - experiences and coping strategies of parents donating 430 haploidentical G-CSF mobilized peripheral blood stem cells to their children. Psycho431 Oncology $2012 ; 21: 168-175$.

434 Kröger N. (eds). The EBMT Handbook, SpringerOpen, 2019, pp. 245-249. 435 https://doi.org/10.1007/978-3-030-02278-5 